\title{
Promoting participation through the universal design of built environments: Making it happen
}

\section{Valerie Watchorn}

Deakin University

\section{Helen Larkin}

Deakin University

\section{Danielle Hitch}

Deakin University

\section{Susan Ang}

Deakin University

\begin{abstract}
Environmental design is a determinant of social inclusion and people's participation in life roles. Design that does not cater for a diverse range of ages, abilities and cultures restricts people's access to, and use of, domestic or public premises. Universal design is an approach that acknowledges diversity of populations and encourages designers to create objects and places that are usable by the greatest majority of users. Although there are potential benefits to the widest application of universal design within society, such application is not mandatory within Australia. This paper presents findings from an Australian qualitative study that explored universal design as a means of facilitating greater environmental access for all. The views of experts working within the field of architecture and environmental access were explored regarding factors that restrict or facilitate application of universal
\end{abstract}


design to the design of built environments. Study findings revealed a number of themes relating to factors that may restrain, 'what's holding us back?' and factors that may facilitate application of universal design, 'making it happen'. These findings have direct relevance to those involved in the planning and design of built environments, policy developers and educators.

Keywords: Universal design, architecture, occupational therapy, built environments, barriers, facilitators, inter-professional education

\section{Introduction}

The design of built environments is a critical determinant of people's ability to participate within their homes and communities regardless of age, gender or abilities (Hitch, Larkin, Watchorn \& Ang, 2012). Professions, who have responsibility for designing the spaces and places inhabited by communities, therefore need to be cognisant of the impact of poor design on the health and wellbeing of individuals and communities (Hitch et al., 2012). Recent sociological and demographic trends, such as ageing populations (Australian Bureau of Statistics, 2009) and the deinstitutionalisation of people with disabilities (Australian Institute of Health and Welfare, 2008), have seen the advancement of legislative and social drivers for designing built environments that are inclusive for all, particularly in relation to public buildings. However, despite these advances many people continue to be unable to participate in their desired or required life tasks and roles due to inaccessible environmental design both in public spaces and private housing.

This paper discusses the social and legislative contexts for incorporating universal design principles as a means of enhancing environmental access for all people. It reports on a qualitative study undertaken that explored the barriers and facilitators to the application of universal design to the design of built environments within Australia from the perspective of key stakeholders and provides new insights into the human rights and social policy drivers for social inclusion for people of all abilities. 


\section{The principles of universal design}

Universal design is an approach to design that acknowledges the diversity of people's needs, and aims to design products and environments that are usable by the vast majority of a population without adaptation or stigma and that continue to meet users' needs throughout their lifespan (The Center for Universal Design, 1997). Thus, universal design "seeks to eliminate discrimination by design and support full social participation for all members of society" (Steinfeld \& Tauke, 2002, p. 165). Universal design is underpinned by an ideology that respect for all avoids stigma, and that designers should be concerned with the needs of an entire population rather than subgroups (Steinfeld \& Tauke, 2002). The Principles of Universal Design (see Table 1) (Connell et al., 1997) are widely considered a means by which built environments can be assessed and as a tool to inform and guide the design of new environments. Despite this, the Principles of Universal Design are not heavily emphasised in architecture education or the profession's body of evidence (Watchorn, Larkin, Ang, \& Hitch, 2013). Steinfeld and Maisel (2012) argue that a lack of understanding exists and that consensus has not yet been reached on what actually constitutes universal design. They outline the main criticisms of the principles that have emerged over time including a view that the principles are more suited for product design and that they lack clarity of purpose (p. 88). In response to these criticisms, Steinfeld and Maisel (2012) have developed eight specific goals for universal design; the first four oriented to human performance; and, the remaining four that address social participation outcomes including cultural appropriateness ( $p$. 90). These goals are aimed at facilitating a more evidence-based approach to universal design practice.

Table 1

The Principles of Universal Design (Connell et al., 1997; (1997 NC State University, The Center for Universal Design)

\begin{tabular}{ll}
\hline Principle & Descriptor \\
\hline (1) Equitable use & The design is useful and marketable to people with diverse \\
& abilities \\
& The design accommodates a wide range of individual \\
(2) Flexibility in use & preferences and abilities \\
& Use of the design is easy to understand, regardless of the \\
(3) Simple and intuitive use & user's experience, knowledge, language skills or current \\
\hline
\end{tabular}


concentration level

The design communicates necessary information effectively to

(4) Perceptible information

(5) Tolerance for error

(6) Low physical effort

(7) Size and space for approach and use the user, regardless of ambient conditions or the user's sensory abilities

The design minimises hazards and the adverse consequences of accidental or unintended actions

The design can be used efficiently and comfortably and with minimum fatigue

Appropriate size and space is provided for approach, reach, manipulation and use regardless of user's body size, posture or mobility

\section{The application of universal design to the design of built environments}

Several factors support the uptake of universal design in today's society. These include demographic trends, legislation and sociocultural influences. While universal design sets its sights beyond aspects of impairment (Steinfeld \& Tauke, 2002), the reality is that the needs of people living with disability influence many people's thinking about environmental design. Two demographic trends are particularly relevant: the increasing proportion of populations aged over 60 years; and, the deinstitutionalisation of people living with disability.

Although maturation does not always correlate with reduced function, an increased prevalence of illness in older people is known to influence ability to access built environments (Spirduso, Francis, \& MacRae, 2004). Alongside and included in this group are people who experience disability. One in five Australians have a disability, with physical disabilities being the most common at 84 percent of this group (Australian Bureau of Statistics, 2004). This is congruent with global estimates that approximately 15 percent of the world's population currently live with disability and that this number is growing (World Health Organization, 2011). In recent decades, the changes in community attitudes to disability have resulted in the move of people with disabilities from large congregate care facilities to smaller communitybased settings. Although, deinstitutionalisation has enabled many people with disabilities and older people to move to, or remain in their own communities, many built environments are not purpose-built and continue to pose barriers to full participation (Australian Institute of Health and Welfare, 2008). Kendrick (2012) acknowledges that while much has been achieved in recent years through a shift in community values, perspective and attitudes, the opportunities for many people with 
disabilities is still restricted by continued social devaluation of them as people and by limited and sometimes inappropriate support systems.

Imrie and Luck (2014) argue that "much of the designed environment is inattentive to the needs of many people" (p. 1315).This statement helps to shift the focus of universal design away from the dominant disability discourse to a broader audience and relevance. Lid (2014) proposes that universal design is not about catering for the needs of one particular user group but to "a larger group of different individuals" (p. 1344), thus reinforcing the earlier views of universal design being related to meeting the needs of the vast majority of the population. Imrie and Luck (2014) argue that if built environments incorporate the elements of universal design more broadly for the general population that there would be in fact a reduction in disability as inaccessible environments can be seen as inherently disabling. If universal design continues to be embedded in the disability discourse, opportunities for social inclusion for many people will not be optimised and indeed some people who would otherwise not be considered to have a disability will continue to be 'disabled' by their environment.

A range of Australian and international legislation support the application of universal design to built environments by legislating against discrimination on the basis of impairment. The Australian Disability Discrimination Act (Commonwealth of Australia, 1992) makes it illegal to discriminate in providing access to, or use of, public premises and draws upon the application of prescriptive Australian Standards to reduce the risk of discrimination and define accessibility from the perspective of physical or sensory impairment (Commonwealth of Australia, 2010; Standards Australia, 2009) However, these Standards are mandatory only for public premises. Internationally, universal design is cited in human rights legislation as being fundamental to people's quality of life (Watchorn \& Layton, 2011). In 2006, the United Nations adopted the Convention on the Rights of Persons with Disabilities (United Nations, 2006). Accessibility is a founding principle of this Convention, and Article 9 explicitly states that signatories will take appropriate measures to ensure equal access to the physical environment (United Nations). The Convention "signifies a paradigm shift in the understanding of disability as a human rights issue" (Lid, 2014, p. 1346). Australia was one of the first countries to ratify this Convention (United Nations, 2013) but there is still a great degree of uncertainty as to how to take this vision and transfer it into practise. 
In Australia, the Livable Housing Design Guidelines (Livable Housing Australia, 2013) are a means by which builders and designers are encouraged to apply the Principles of Universal Design to make private and public housing visitable and to facilitate aging-in-place. These guidelines are the first Australia-wide attempt to operationalise to any great extent the Principles of Universal Design. While other States and Territories of the Commonwealth and relevant industry organisations have published guidelines in this area, this is the first attempt to set measurable targets for government and industry representatives regarding housing design. However, Bringolf (2011) noted that developers and builders appear reticent to voluntarily accommodate the guidelines and targets into popular housing design. While Australian building standards and disability discrimination legislation is in place for all public premises, there is also a reluctance to take the next step to mandate universal design guidelines for all housing. This concern by Bringolf appears to be validated by the findings by Ward (2014) who has subsequently reported that the national voluntary targets for the percentage of all new housing to incorporate minimum access features by 2020 are unlikely to be met. However, exemplars of good practise within the local government sector do exist where local planning initiatives have resulted in an increased supply of housing that incorporates livable housing features designed to meet the needs of current and future residents (Neilson, 2014). It would appear that if there is sufficient good will and commitment at a local council level, that change is possible and achievable.

\section{Factors influencing the application of universal design}

Published literature reveals little information on the forces that impede or support the application of universal design to the design of built environments. In her discussion on the future of universal design, Bringolf (2008) acknowledges the potential influence that legislation, education, terminology and scientific evidence has on the uptake and application of universal design. She notes that a lack of strong evidence supporting the application of universal design and the use of language that is somewhat unclear and not well recognised, are significant barriers. Bringolf also argues that universal design is widely associated with the specific intention of improving access for people with disabilities and that this relationship has potentially impeded the broader understanding and application of universal design. Associating universal design with the concept of disability may have unintentionally influenced 
designers to ignore the overall challenge of universal design, and to restrict design to meet the explicit accessibility standards and disability discrimination legislation.

In her review of the application of universal design specifically to the Australian housing market Bringolf (2011) identified four key barriers. These were: perceived additional costs; use of language and terminology that promotes people with disabilities and older people as 'other'; societal attitudes and marketing practices that view universal design negatively; and, finally the structure of a mass market housing industry where the implementation of universal design is perceived to only be possible via legislative means.

While lack of agreement around terminology appears to be an ongoing issue, universal design continues to be relevant to the design of built environments in today's society as a means of addressing the broadest needs of people and populations regardless of abilities, needs and roles. Steinfeld and Maisel (2012) acknowledge that although the term universal design is not well understood, there is increasing understanding and application of the broad principles and concepts by leading architects across the world, although it may not necessarily be labelled as such by practitioners. Thus the term, universal design is generally not widely understood or systematically applied within the relevant industries and greater understanding of the potential barriers and drivers to the implementation of this concept is needed.

\section{Study aims}

This study was part of a larger inter-professional education study that introduced universal design into the curricula of undergraduate architecture and occupational therapy students at a regional campus of a large Australian university (Hitch et al., 2012; Larkin, Hitch, Watchorn, Ang, \& Stagnitti, 2013; Watchorn et al., 2013). As part of this study, the views of key industry stakeholders were explored to inform teaching initiatives. This paper presents findings from focus groups and interviews with key stakeholders that aimed to explore factors considered to act as barriers and facilitators to the implementation of universal design in the design of built environments. 


\section{Method}

This study was approved by the Human Ethics Advisory Group, Faculty of Health, Medicine, Nursing and Behavioural Sciences, Deakin University, Australia. Qualitative methodology, specifically a phenomenological approach using openended questions, was used to explore the everyday experiences and views of participants about key issues and industry practices (Hitch et al., 2012; Rice \& Ezzy, 1999).

\section{Participants}

Judgment sampling was used to recruit participants, as members of the project steering committee nominated informants known to have expertise and experience in universal design and built environments (Hitch et al., 2012). Snowball sampling also occurred, as participants recommended others who were considered as experts in the area. Recruitment continued until the point at which saturation occurred and no new data was seen to be emerging (DePoy \& Gitlin, 2005).

A total of 76 people were invited to participate with 28 individuals participating in one of three scheduled focus groups $(n=16)$ or a telephone interview $(n=12)$. Focus group participants were recruited from two major metropolitan centres in the same State while telephone interview participants were located across three mainland Australian States.

Of the 28 participants, $75 \%(n=21)$ were female. Almost half $(46 \%)$ were aged $45-54$ years with a further $21 \%$ aged $35-44$ years and $14 \%$ aged $55-64$ years. All participants were experienced in terms of building design and accessibility, reporting a mean of 20.22 years working in the field. Four professional disciplines were evident: occupational therapists $(34 \%, n=9)$, access consultants $(29 \%, n=8)$, architects $(11 \%, n=3)$, and managers of services that support people with disabilities $(18 \%, n=5)$. The background of remaining participants included law, higher education and other health professional roles. Several participants $(33 \%, n=4)$ also selfidentified as having a disability and brought to the study both professional and personal experiences of environmental and universal design. When considering the high incidence of women in the sample, the authors view this as relating to the representation of what is a female dominated profession of occupational therapy and the trend towards many access consultants coming from the same profession. 


\section{Data collection}

An introductory email was sent to key informants inviting participation and providing a plain language statement outlining the study (Hitch et al., 2012). Informed consent was gained prior to participation, and a questionnaire used to collect demographic information prior to the focus group or telephone interview. Three focus groups were held with a facilitator and observer/notetaker present, while 12 telephone interviews were conducted by a single interviewer. All focus groups and telephone interviews were digitally recorded and transcribed verbatim. Given the use of judgment sampling, the steering group was aware of the potential for assumptions and personal views to impact on the data and this was discussed openly in the analysis and integration phases of the study.

\section{Data analysis}

Each transcript was read in its entirety to enable the researchers to become immersed in the data. Thematic analysis was then undertaken, with codes being assigned for interpreted meaning on a line-by-line basis. Each transcript was coded separately and a list of codes was generated at the conclusion of this process. The codes were then clustered into themes that summarised the data.

\section{Rigour and trustworthiness}

All four aspects of trustworthiness identified by the Rosalind Franklin Qualitative Research Appraisal Instrument (RF-QRA) (Henderson \& Rheault, 2004) were considered in this study. Credibility (internal validity) was enhanced by recruitment of participants from a range of professional backgrounds, thereby ensuring that multiple sources and perspectives were captured in the data. While generalisability (external validity) is not the aim of qualitative research, the sample included representatives from the population of key informants and stakeholders across the field of environmental and universal design. The noticeable exception to this was the predominance of female participants, as many professions involved in the construction of built environments are male dominated (Preston \& Whitehouse, 2004). Dependability (reliability) was promoted by peer examination of the final structure of themes. Confirmability was enhanced by the presence of an observer/notetaker at the focus groups, and regular review meetings of all research team members. 


\section{Results}

A number of sub-themes emerged from the data relating to the barriers ('what's holding us back?') and facilitators ('making it happen') that influence the application of universal design to built environments.

\section{What's holding us back?}

The theme of 'what's holding us back' included all factors that participants felt were restraining or damaging to the promotion of universal design within the community. Four sub-themes emerged: the dangers of the disability paradigm; what's missing; competing with sustainability; and the bottom line.

\section{The dangers of the disability paradigm}

The historical and current focus on disability or aging was seen as a narrow perspective and many participants felt it was time the debate around universal design expanded to encompass all sections of the community and increase its general relevance.

I find you start talking about disability, and architects and people in local government, their eyes start to glaze over. But as soon as you start talking about it in a broader community context of every single one of us could benefit from this, then there's a different view of it.

We've got the symbol for the disabled toilet. Well, the toilet's not disabled. We don't use a language that's accessible. It's disabled somehow ... We find in communication with architects and builders that's what they refer to, everything is disabled this and disabled that, because that's the way their thinking is all the time.

The disability paradigm was also felt to encourage a homogenised view of people with disabilities. Many participants made distinctions between the needs of different groups of people, for example, people with vision impairment, intellectual disability or autism, but noted that current practice in universal design seems to encourage a 'one size fits all' response. 
We often label people with disability under the one category. We say we cater for people with disability; well we need to be a bit careful because there are various types of disability. That's number one, and even with the same type of disability they're all unique individuals so we break down even further. It's like saying we cater to all women. Well we don't necessarily know that just because of your gender, it doesn't mean you all uniformly think the same and have the same needs.

\section{What's missing?}

Participants identified four key factors that are missing from the discourse around universal design: lack of action; lack of education; lack of information; and, lack of awareness. There was a sense from many participants that momentum has been lost in recent years and that support for universal design is going through something of a lull in Australia.

We talk about it a lot, everyone agrees with it philosophically but it doesn't happen.

When we say there's a long way to go, I suppose in some way that implies that we are moving along a path or we're on a journey, but I don't think we are.

Participants reported a general lack of understanding by others about their work around universal design. They noted that few people are interested in this area, and they are usually dealing with stakeholders who have little, if any, understanding of universal design.

I don't think the community really understands the difference between universal design and accessible design, and that's then leading to misunderstandings by builders and developers, and policy makers.

Related to this need for education was an identified lack of complete or good quality information about universal design, as stakeholders remained unaware of the potential benefits and advantages. 
Do we know what we're talking about? I don't think we should all scurry away and do endless research and have everything sorted out before we do our marketing or change things, but it worries me. I wonder if we are advising about the right thing to do.

\section{Competing with sustainability}

A strong theme across participants was a sense that universal design compares unfavourably to sustainability as a trend in environmental design. In fact, many participants identified the drive towards sustainability as a barrier to the development of universal design. Some stated that universal design is by its very nature sustainable, and therefore one begets the other. However, others identified universal design as a separate issue, and felt that, in comparison to sustainability, it had fallen 'out of fashion'.

Universal design is not actually all that far removed from ecologically sustainable design principles in that we're trying to move people forward into understanding the materials we use affect our health and they do affect our wellbeing.

Some participants advocated for universal design to be marketed in a more desirable way.

This area isn't very sexy at times. When you talk about inclusive design or universal design, it's tagged with disability and disability isn't sexy.

\section{The bottom line}

A significant barrier to the implementation of universal design identified by participants was economic pressures, both real and perceived. Many commented that measures aimed at promoting universal design are seen to be more costly, leading to resistance from some quarters.

The building industry is still going to hold it back; they're always going to say that things are too costly because with universal design, everything has to be bigger. 
Some participants indicated that economic factors didn't have to be barriers if they were projected and perceived in more positive ways. The notion of mutual benefit was used to justify spending and moving away from the disability paradigm was again suggested.

You can't have good teaching, good medical practice or good architecture on the cheap.

So while yes, there are people who will connect through stories and experience and life ... we've got to be smart and have the 'what's in it for me' kind of hat on, whether it be through business awards or there's some sort of financial incentive.

Over in America they promote universal design in housing by talking about the features that can be incorporated into their housing that can be used to help sell the property at a later date. So, rather than talking about aging or disability, they talk about you've got something unique and different in your home that will help with the resale of your home.

\section{Making it happen}

In relation to 'making it happen' participants identified four main factors that promoted development of universal design in the community: champions; a future orientation; societal influences; and life experience.

\section{Champions}

Champions can be individuals or organisations who demonstrate willingness or enthusiasm for universal design, or advocate for its implementation at multiple levels of influence. Many participants identified champions or showcase examples in their responses around universal design, both to illustrate what is possible and when describing how to overcome some barriers already identified.

That's what we do pretty much every day is advocate, even though there's legislation there, we still advocate on behalf of people with disabilities to make sure that the building does comply over and above the standards. 
The other form of championing was the production of showcase examples of good practice in the area. The main benefit of examples cited by participants was their ability to inspire and stimulate innovation, but many stated that these examples simply are not well known enough to have a substantial impact.

There's pockets of excellence and expertise in the field, both in Australia and overseas, but there seems to be an overwhelming need for better connection between various people doing it.

\section{The long term view}

Participants identified that the most successful approaches to universal design tended to take a longer term view. Universal design was seen as an ongoing and evolving issue, with changes in users' needs and abilities expected and taken into account. While difficulties in predicting such changes were acknowledged, participants stated it was worth taking time to try and ascertain this if a built environment is going to have sustainable access. Discussions of future orientation also acknowledged that multi-stakeholder collaboration from an early stage was thought to promote better long term planning and prediction.

Solutions to existing barriers within the community would be managed and funded for the most logical, long term solution. For example: buildings that don't currently have lifts should be installed with lifts. It's a high cost thing to do, but if you did it, it would make a whole lot of buildings more accessible.

\section{Societal influences}

Participants identified a range of socio-cultural trends and changes which have the potential to facilitate the application universal design. Greater participation of people with disabilities in the broader community, and the ageing trend seen in many countries were strong demographic factors that participants felt could be exploited when marketing the need for universal design.

I think people are living in the community in a way they never used to, so people living with high levels of disability that 30 years ago they would not have been. 
I think the ageing of our community is pushing it forward, and I hear the voice of older people now where I don't think we heard that 20 years ago, and they're a loud voting relation [sic] with income, so that may be changing things. But we need to work with them, not hear the voices in isolation.

A growing awareness of the consequences of exclusion, and its reframing as a human rights issue was also identified as a socio-cultural shift that highlights how essential universal design is to all. Occupational therapists in particular, identified that exclusion from access, and therefore participation, is becoming less acceptable in contemporary societies.

Participation, we all wish to participate in this range of stuff, what is it that enables us and what stops us, and I think sometimes the architects might be horrified to realise that their designs are stopping people. It's occupational deprivation.

\section{Life experience}

The positive influence that life experience has on being more inclined to promote universal design was repeatedly identified. This was particularly discussed in relation to undergraduate education, with the recognition that many students, who are design professionals of the future, lack substantial general life experience by virtue of age. Many participants argued for students to be provided with opportunities to gain 'first hand' or other experience of disability. Such experience was always related to knowing someone with a disability, showing the strength of the current focus on disability and illness in relation to universal design.

Until people personally experience issues with family members they don't really have any understanding.

Even just walking around the street with someone in a wheelchair, and watching them drift off on a slope that shouldn't really be there. 
The result of these life experiences was seen to be greater empathy for the needs of others. However, it was acknowledged that this doesn't always develop, and that denial can be a strong counter force.

You can even have people with a wheelchair user in their family and they still don't join the dots because in their head the idea of disability it's 'well tough luck mate, I'm glad it didn't happen to me, but I can see life is difficult and we'll just help you the best we can. We just won't go to the places that you can't get in, we won't invite you round, and we'll just come to your house'. They just think that having a disability and being excluded is normal.

Aside from professional education, many participants advocated increasing educational opportunities around universal design. Two potential targets were identified as requiring this approach - the general community and the building trades.

Really target the public to say, look, don't talk about people with disability or aging people as 'them' as you are going to become one of 'them'.

\section{Discussion}

Findings from this study support Bringolf's (2008) view that an association between universal design and the disability paradigm may hinder progress of the application of universal design. A familiar and understandable language was acknowledged to be important to policy development, public perception and academic debate but was also noted to be potentially hazardous to the design of environments that are truly designed for all users and not simply responses to prescriptive accessibility standards (Bringolf, 2011). The variation in terminology is recognised by Steinfeld and Maisel (2012) who argue that while the term is not commonly understood, there is an increasing uptake of design processes, which although not labelled as universal design, better recognise the diversity of abilities within populations and the design of built environments accordingly. There has also been discussion about the value of terms such as universal design and whether industry, educational and other groups should focus more on design that is usable by all or simply to talk about good 
design in general (Moore, 2014). Others prefer to focus on the importance of the implications of universal design on the design process (Petrén, 2014) rather than focussing on the preferred terminology

A strong, and potentially negative, connection between the language used when talking about disability and universal design was acknowledged both in this study and by Bringolf (2008). It is interesting to note that although this study identified the 'dangers of the disability paradigm' and the need to broaden perspectives on universal design, participants' discussion on the factors that might facilitate application of universal design actually reverted to the disability paradigm. For instance participants felt that it would be beneficial for design students to gain 'first hand' experience of the difficulties encountered by a person living with disability. It appears to be difficult to break free from a direct one-dimensional relationship between universal design and disability.

In this study, the disability paradigm was felt to encourage a homogenised view of people with disabilities. This has previously been highlighted by Imrie (2012). By acknowledging that an environment should be "usable by all people, to the greatest possible extent, without the need for adaptation and specialised design" (The Center for Universal Design, 1997, p. 1), specific design elements or features that may be assistive to an individual or specific groups may be discounted (Imrie, 2012). In acknowledgement of this interpretation, the Convention on the Rights of Persons with Disabilities specifically states that "'universal design' shall not exclude assistive devices for particular groups of persons with disabilities where this is needed" (United Nations, 2006, Art. 2). It appears that there is an identified risk of not acknowledging a population's diversity by using the term 'universal'.

Education was acknowledged by participants in this study as a missing factor in the discourse around universal design. This was also acknowledged by Bringolf (2008) who identified universal design as a low priority for designers and design schools. Content on universal design may be included as a specific type of design relating to disability and accessibility and not a "fundamental part of design thinking" (Bringolf, 2008, p. 47). During their participation in the larger aspect of this study, undergraduate occupational therapy and architecture students also perceived the importance of integrating universal design content throughout a course rather than as a stand-alone unit or aspect of teaching (Watchorn et al., 2013). 
Interestingly, the view of participants in this study was that universal design needed to compete with sustainability initiatives which were thought to have the greater prominence in design processes. However authors such as Steinfeld and Maisel, (2012) increasingly see universal design as a component of sustainability rather than having to compete with it. In 2008, the Queensland Department of Public Works, defined sustainable housing as one where "the occupant can move around more easily, feel safer, save money and use resources like energy and water more efficiently. ... (a home) that will meet a family's needs through all stages of their lives" (Queensland Department of Public Works, 2008, p. 2). Such a definition makes clear that universal design is more than just adopting prescriptive and minimal standards for accessibility. The Department further defined ecologically sustainable development as including the need to integrate social considerations into the design process and the need to ensure "fairness and equal access to opportunities both in our lifetimes as well as to future generations (p. 2). These sentiments appear to sit very comfortably within the Principles of Universal Design and appear to support a view that universal design does not need to compete with sustainability but instead is an integral element of sustainability. Further to the consideration of costs as part of sustainability, Imrie and Luck (2014) comment that greater availability of built environments that incorporate principles of universal design may reduce the cost of rehabilitation for people with health conditions, emphasising the prohibitively high cost of retro-fitting both public buildings and private residences to cater for changed needs within people's lifetimes or at critical life events.

In a North American case study by Gossett, Mirza, Barnds and Feidt (2009), a nexus between universal design and sustainability was identified whereby design features seen to support the application of universal design principles also supported the principles of sustainable building design. Findings from this study suggest that a relationship between universal design and sustainability could be synergistic but may also be detrimental to universal design. The relationship between sustainability and universal design appears therefore to be an important opportunity to progress the case for universal design, although further investigation is required.

Participants in this study reported that it was important to have champions of change to be powerful influencers for the uptake of universal design practice and processes. The work undertaken by Livable Housing Australia (2013) through the Livable Housing Guidelines is one example of promoting champions of change 
through partnership with key housing industry, government, community and consumer stakeholders. However, as discussed the targets for accessible housing as set for 2020 are unlikely to be met (Ward, 2014) and that these voluntary codes (while an important driver and precursor to change) will not be sufficient to bring about achievement of aspirational targets (Ward, Franz, \& Adkins, 2013). Steinfeld and Maisel (2012) argue also that some sort of legislated, certification process with inbuilt review and approval processes will bring about real change and more importantly ensure that "producers, building owners, and service businesses deliver good results when they make that claim" (p. 91).

Economic pressures, both real and perceived, were noted by participants in this study to be a significant barrier to the implementation of universal design. This aligns with findings from Bringolf's (2011) investigation into the application of universal design in the Australian housing sector. Findings from this study also acknowledge potential fiscal benefits of universal design. To date there has been little economic evaluation of universally designed buildings and environments. Given the complexity of such a task this is not surprising. Although proponents of universal design strongly argue that the economic benefits of universally designed buildings and transport systems far outweigh potential costs of implementation (Odeck, Hagen, \& Fearnley 2010; Schraner, De Jonge, Layton, Bringolf, \& Molenda, 2008), more detailed economic analyses of this practice area is warranted.

In this study, the identification of individual champions and the showcasing of effective projects were seen as useful forms of advocacy to advance this field of practice. Interestingly, in his attempt to delineate a research agenda for universal design, Prieser (2008) acknowledges that case studies, and what could be considered champions, of products, buildings and environments are the primary form of research that exists in this area. It could be posited that greater promotion of such case studies to the community of design stakeholders could enhance endeavours in this field. Taking a future orientation to building design and life experience were also seen as key factors in the advancement of universal design. The inclusion of real-life experiences within undergraduate education, such as those reported by Watchorn et al., (2013), can be seen to be of potential value in this area.

As an exploratory study, these findings contribute new insights into factors that may restrain or facilitate the application of universal design principles to built environments. However, there are some limitations which impact on the applicability 
of findings. The Australian context features unique legislative Standards and work practice contexts which may not be relevant to other countries (Hitch et al., 2012). Additionally, while the sample was diverse and representative of identified 'experts' in the field, it was not representative of the wide range of people in the building industry such as builders and building designers who may not be as committed to the principles of universal design (Hitch et al., 2012). Despite these limitations, the study addresses an identified gap in the existing literature and highlights potential factors that may be seen to restrain or facilitate the application of universal design features in Australian environmental design. Possible future directions for research include further exploration of the relationship between universal design and sustainability, economic analyses of universally designed buildings and environments and more detailed investigation of how the factors identified within this study impact on the application of universal design to the design of built environments.

\section{Conclusion}

The design of the built environment in terms of public spaces and private housing is a determinant of social inclusion and people's participation in their chosen and required life roles and activities. Universal design is a design approach that, when applied to built environments, can make buildings and communities usable by a wide range of people and this potentially has far-reaching consequences to the social participation of individuals and communities at large.

This study was part of a larger study that focused on the inter-professional education of occupational therapy and architecture students in relation to universal design practice. If the uptake of universal design is to be advanced, the education of design students and other related disciplines is imperative. Future design practitioners need to be able to make the economic, sustainable and equity arguments for the benefits of built environments that don't discriminate, regardless of age, race, gender, ability, ethnicity, sexual orientation and culture. This study contributes insights into understanding some of the factors that may influence the application of universal design more broadly within the community so that all people can go about their everyday lives and roles with as few built environmental barriers as possible; good design, usable by all. 


\section{Acknowledgements}

The authors acknowledge the support of a grant from the 2010 Deakin University Strategic Teaching and Learning Grant Scheme (STALGS). The authors also acknowledge the contribution of the Deakin University Design 4 Diversity research team and participants and the technical and administrative support of the School of Health and Social Development, the School of Architecture and Built Environment, the Division of Equity and Diversity and the then Knowledge Media Division and Institute of Teaching and Learning.

\section{References}

Australian Bureau of Statistics. (2009). 3201.0-Population by age, and sex: Australian States and Territories. Retrieved from http://www.abs.gov.au?Ausstats/abs@nsf/mf/3201.0

Australian Bureau of Statistics. (2004). 4430.0 - Disability, ageing and carers, Australia: Summary of findings, 2003. Retrieved from http://www.abs.gov.au/AUSSTATS/abs@.nsf/Lookup/4430.0Main+Features1 2003?OpenDocument

Australian Institute of Health and Welfare. (2008). Disability in Australia: Trends in prevalence, education, employment and community living (Bulletin no. 61). Canberra: AlHW.

Bringolf, J. (2008). Universal design: Is it accessible? Multi: The RIT Journal of Plurality and Diversity in Design, 1(2 Spring/Summer), 45-52.

Bringolf, J. (2011, June). Barriers to universal design in Australian housing. Paper presented at the International Conference on best practices in universal design at FICCDAT. Toronto, Canada. Paper retrieved from http://udeworld.com/presentations/papers/Bringolf\%20UD\%20Housing\%20FI CCDAT.pdf

Commonwealth of Australia. (2010). Disability (access to premises-buildings) standards 2010. Canberra: Commonwealth of Australia.

Connell, B. R., Jones, M., Mace, R., Mueller, J., Mullick, A., Ostroff, E., Sanford, J., Steinfeld, E., Story, M., \& Vanderheiden. G. (1997). The principles of universal design - Version 2.0. Raleigh, NC: North Carolina State University. Retrieved

from http://www.ncsu.edu/www/ncsu/design/sod5/cud/about ud/udprinciplestext.ht $\underline{m}$

Commonwealth of Australia. (1992). Disability Discrimination Act of 1992$2013 \mathrm{C} 00022$.

DePoy, E., \& Gitlin, L. N. (2005). Introduction to research: Understanding and applying multiple strategies ( $3^{\text {rd }}$ ed.). St Louis: Elsevier Mosby. 
Gossett, A., Mirza, M., Barnds, A., \& Feidt, D. (2009). Beyond access: A case study on the intersection between accessibility, sustainability, and universal design. Disability and Rehabilitation. Assistive Technology, 4(6), 439-450. doi:10.3109/17483100903100301

Henderson, R., \& Rheault, W. (2004). Appraising and incorporating qualitative research in evidence-based practice. Journal of Physical Therapy Education, 18(3), 35-40.

Hitch, D., Larkin, H., Watchorn, V., \& Ang, S. (2012). Community mobility in the context of universal design: Interprofessional collaboration and education. Australian Occupational Therapy Journal, 59(5), 375-383.

Imrie, R. (2012). Universalism, universal design and equitable access to the built environment. Disability \& Rehabilitation, 34(10). 873-882.

Imrie, R., \& Luck, R. (2014). Designing inclusive environments: Rehabilitating the body and the relevance of universal design. Disability and Rehabilitation, 36(6), 1315-1319.

Kendrick, M. (2012). As the years pass: Reflections on the last twenty-five years and looking forward. Interaction: The Australian magazine on intellectual disability, 25(3), 6-15.

Larkin, H., Hitch, D., Watchorn, V., Ang, S., \& Stagnitti, K. (2013). Readiness for interprofessional learning: A cross faculty comparison between architecture and occupational therapy students. Journal of Interprofessional Care. 27(5), 413-419. doi; 10.3109/1356118202013.779233

Lid, I. M. (2014). Universal design and disability: An interdisciplinary perspective. Disability and Rehabilitation, 36(16), 1344-1349.

Livable Housing Australia. (2013). About livable housing Australia. Retrieved from http://livablehousingaustralia.org.au/

Moore, P. (2014). A history of UD: Today's exemplars and tomorrow's opportunities. Assistive Technology Research Series, 35, 5-6. Universal Design 2014: Three days of creativity and diversity, IOS Press Ebooks. doi: 10.3233/978-1-61499403-9-5

Neilson, S. (2014). Banyule City Council-Liveable Housing Guidelines: "Improving housing for people across their lifespan". Universal Design Conference, Sydney, New South Wales, Australia, 20-21 August 2014. Retrieved from http://www.universaldesignconference.com.au/presentation/banyule-citycouncil-liveable-housing-guidelines-improving-housing-for-people-acrosstheir-lifespan/

Odeck, J., Hagen, T., \& Fearnley, N. (2010). Economic appraisal of universal design in transport: Experiences from Norway. Research in Transportation Economics. 29, 304-311.

Petrén, F. (2014). Turning societal challenges into creative opportunities. Assistive Technology Research Series, 35, 11-12. Universal Design 2014: Three days of creativity and diversity, IOS Press Ebooks. doi: 10.3233/978-1-61499-4039-11

Preiser, W. F. E. (2008). Universal design: From policy to assessment research and practice. International Journal of Architectural Research. 2(2), 78-93.

Preston, A., \& Whitehouse, G. (2004). Gender differences in occupation of employment in Australia. Australian Journal of Labour Economics, 7(3), 309328. 
Queensland Department of Public Works. (2008). Smart and sustainable homes design objectives. Technology and Development Division, Queensland Department of Public Works; Brisbane. Retrieved from http://www.hpw.qld.gov.au/sitecollectiondocuments/smarthousingdesignobject ives08.pdf

Rice, P. L., \& Ezzy, D. (1999). Qualitative research methods: A health focus. Melbourne, Australia: Oxford University Press.

Schraner, I., de Jonge, D., Layton, N., Bringolf, J., \& Molenda, A. (2008). Using the ICF in economic analyses of assistive technology systems: Methodological implications of a user standpoint. Disability \& Rehabilitation, 30(12/13), 916926.

Spirduso, W., Francis, K., \& MacRae, P. (2004). Physical dimensions of aging $\left(2^{\text {nd }}\right.$ ed.). Champaign, IL: Human Kinetics.

Standards Australia. (2009). AS 1428.1-2009 Design for access and mobility. Part 1: General requirements for access - new building work. Sydney: SAl Global Limited.

Steinfeld, E., \& Maisel, J. L. (2012). Universal design: Creating inclusive environments. New Jersey: John Wiley \& Sons Inc.

Steinfeld, E., \& Tauke, B. (2002). Universal designing. In J. Christophen (Ed.), Universal design: 17 ways of thinking and teaching (pp. 165-189). Husbanken. Retrieved from http://regelverk.husbanken.no/regelvrk/hbnr.nsf/B1D046237F2714D7C1256B4B003921F1/\$FILE/7f34e.pdf

The Center for Universal Design. (1997). Principles of universal design. Retrieved from http://www.ncsu.edu/ncsu/design/cud/about ud/udprinciples.htm

United Nations. (2006). Convention on the rights of persons with disabilities New York: United Nations. Retrieved http://www.un.org/disabilities/convention/conventionfull.shtml

United Nations. (2013). Convention and optional protocol signatories and ratifications. Retrieved from http://www.un.org/disabilities/countries.asp?navid=17\&pid=166

Ward, M. (2014). Universal housing design: Let's get going! Universal Design Conference, Sydney, New South Wales, Australia, 20-21 August 2014. Retrieved from http://www.universaldesignconference.com.au/presentation/universalhousing-design-lets-get-going/

Ward, M., Franz, J., \& Adkins, B. (2013). Livable housing design: Who will take responsibility? State of Australian Cities Conference, 26-29 November, Sydney, Australia. Retrieved from http://www.soacconference.com.au/wpcontent/uploads/2013/12/Ward-Economy.pdf

Watchorn, V., Larkin, H., Ang, S., \& Hitch, D. (2013). Strategies and effectiveness of teaching universal design in a cross-faculty setting. Teaching in Higher Education. 18(5), 477-490. doi: 10.1080/13562517.2012.752730

Watchorn, V., \& Layton, N. (2011). Advocacy via human rights legislation: The application to assistive technology and accessible environments. Australian Journal of Human Rights, 17, 117-138.

World Health Organization. (2011). World report on disability. Geneva: World Health Organization.

from http://whqlibdoc.who.int/hq/2011/WHO NMH VIP 11.01 eng.pdf 


\section{Biographical notes}

Valerie Watchorn is a lecturer in the Deakin University occupational therapy program. Valerie has worked as an occupational therapist in service provision and education within the disability sector both in Australia and overseas. Areas of professional interest include universal design, environmental design, assistive technology, occupational therapy practice education and teaching and learning within higher education.

Helen Larkin brings to her academic position as senior lecturer in the occupational therapy program over 30 years' experience in the disability sector in service provision, management and research. Her teaching and research interests include curriculum development, inter-professional education, reflective practice and work integrated learning. Helen has been recognised through both university and national teaching awards.

Danielle Hitch is a fieldwork educator and lecturer in the Deakin University occupational therapy program. She has worked clinically in both the United Kingdom and Australia for over a decade and is a PhD candidate. Her areas of interest include mental health, knowledge brokerage, inclusive education and social justice.

Susan Ang is a qualified architect and a senior lecturer in design and communication in the architecture program. She has fifteen years of industry experience in residential and commercial projects. Her academic interests and expertise are in socially responsible architecture and intercultural and crossdisciplinary built environment design education. 